\title{
How Niche Is Niche? Measuring Individual's Perception of Technology Niche
}

\author{
Mehdi Darban \\ Louisiana State University-Shreveport \\ mehdi.darban@1sus.edu
}

\begin{abstract}
Despite the recent advent and popularity of niche technologies, less is known about the adoption dynamics of such systems. In a quest for understanding and differentiating between mainstream vs. niche technologies, and the way such differences influence individuals' information systems (IS) behaviors, the study argues that a scale to measure individual's niche perception in the domain of technology usage is needed. Basing on the main argument of the Optimal Distinctiveness theory, the study introduces a muchneeded conceptualization and operationalization of niche technology perceptions in the literature. Across three studies, we test a typology of perceived niche and develop and validate a 4-item scale to measure individuals' niche perceptions in IS domain. As a result, academic researchers may now rely on the developed scale to investigate the dynamics of users' IS behaviors by incorporating the potential effect of the perceptions of niche in their future research studies.
\end{abstract}

\section{Introduction}

A growth in people's interest for niche products i.e. more individualized products tailored to the needs of a very specific target group rather than to the mass market - has been observed for the past years and has received widespread attention [12, 16, 36, 40, 42, 45]. We may also observe such a trend in the introduction and adoption of IS artifacts. An example of this might be the relatively successful launches of niche social networking sites (SNSs), such as Ello, Flixster, ResearchGate, and imeem. These niche systems have been attracting the users of the more mainstream SNSs (e.g., Facebook and LinkedIn), as recent reports show that, for instance, people are abandoning Facebook to join to other SNSs [21]. Thus, by differentiating themselves, niche SNSs are targeting smaller mass of users and markets, which represent an option for companies beyond saturated mass markets. Niche
SNSs are aiming to attract a group of people who are very dedicated to a specific topic or activity and bring them together. Designing and conveying their unique characteristics, niche information systems (including SNSs) are focusing on a smaller market for the advantages of higher prices and less competition. Moreover, what starts out as a relatively small market for a niche product can offer growth potential [27], and thus develop into a larger and more attractive market over time [12]. A product that has been successful in a niche position can, therefore, gain a head start from competitors when the niche market grows [9]. As one example, the introduction of iPad, as an initially niche product by Apple, which later managed to successfully grow into a mass market [29].

The extant research mostly conducted to investigate the IS adoption dynamics of mainstream information systems and apps. While, the popularity of niche versus mainstream systems, especially in the contexts such as SNSs, requires research to look at the concept of niche in individuals' IS behaviors. In words, to depict a better picture of the usage patterns of recent niche systems, it is important to study how an adopter perceives the level of niche-ness of a system. However, the measurement of the perception of niche-ness of a system has not received any empirical attention. This study focuses on understanding what is meant by 'niche technology', specifically in the context of SNSs, and develops an instrument to gauge the perception of niche.

A scale to measure this degree of niche-ness (and the degree of each of the sub-dimensions of niche that are discussed later) would allow an estimate to be made of the amount of perceived niche of an IS. This scale could be used not only in the creation of a niche IS but also in the continuous monitoring of existing niche systems and in basic research in IS usage behavior of individuals. Practitioners view the nicheness level of a product as a main factor to differentiate a product from others [25], and as a central driver of user preference and usage [47]. At present there is no scale measuring the perceived niche of an IS, or even a 
clear definition of what constitutes a niche IS compared to a non-niche IS.

Before presenting the detailed results of this study, a brief review of the perceived niche construct and its potential relevance to issues pertaining to the analysis of niche seeking IS adopter behavior, will be provided. Then the major steps of the development of the scale, including detailed tests of the reliability and validity of the scale, are being discussed. Finally, key findings of the research are reviewed and discussed.

\section{Background: perceived niche}

Optimal Distinctiveness theory (ODT) suggests that people reconcile opposing needs for assimilation and differentiation through their group memberships [6]. This literature suggests that people have a fundamental need to belong to social groups and, at the same time, have a fundamental need to defend their individual identities (distinctiveness). Individuals tend to apply strategies to achieve the sense of distinctiveness. One strategy is to develop high perceptions of niche about the product they are using (e.g., perceptually enhance the distinctiveness of an SNS); hence they convey their membership to a distinct group of users. In short, the distinctiveness of an IS is not necessarily something that is embedded in its structural reality but can be a perception residing in the mind of users and sensitive to the social context [4].

The conspicuous consumption literature also provides further explanation for such a phenomenon. The tendency of an individual to purchase and exhibit expensive goods is known as conspicuous consumption [46]. As Schaefers [4] indicates Veblen's [46] early understanding of conspicuous consumption was limited to the process of using publicly visible and luxurious products to signal social status. More recent researches have extended the conspicuous consumption notion to integrate multiple dimensions of social needs $[21,18]$. Similarly, Schaefers [40] argued that using niche products, defined as products possessing a higher degree of specificity and uniqueness than corresponding mass-market products, is a means to satisfy one's desire for an improved social standing. People are more likely to seek to differentiate themselves with niche products that contribute to selfexpression, than mainstream products that are universally adopted and unlikely to impact a person's ability to express their identity [4]. In fact, the use of niche product helps the user achieve high social visibility since those products are easily recognizable from mainstream products. Thus there is an agreement in the literature to view niche products as products for which the use or display of them brings esteem to the owner, apart from their functional utility. Hence, niche products enable consumers to satisfy both psychological and functional needs. Consequently, we may argue that niche SNSs are being designed not only to address the functional needs of specific cluster of users (e.g., establishing collaborative research for scientists and researchers by ResearchGate) but also to satisfy users' psychological needs of being distinct from other professionals (i.e., a scientist rather than a general professional) [6].

The extant literature perceived that a product is either niche or not niche (i.e., mainstream). While, as we mentioned above, ODT argues that the sense of distinctiveness of an IS product is a perception residing in the mind of its users and sensitive to the social context [4]. Hence, adopters may recognize that not all niche products are equally niche. As Kemp [26] has pointed out "water" could be viewed by different observers as either a niche or as a necessity depending on who wants water or why. Surprisingly, a product could also be either a niche or a necessity for the same person in different situations [47].

In fact, a system might be perceived highly as a niche one by a user while another user may find it not niche. In addition, there is a distinction between niche systems associated with an upper range of niche and those associated with the lower range of niche. For instance, an SNS may be defined as a niche SNS, but all the SNSs considered niche may not be perceived equally. 'LinkedIn' for instance, may seem a niche SNS among the general population since it is for professionals and it is for particular social activities (e.g., finding a job, etc.). Similarly, ResearchGate may be perceived even more niche compared to LinkedIn, as it is for a specific cluster of professionals (i.e., researchers). Another example would be 'Ello' which may have a higher niche image since it is an SNS for a specific group of professionals (i.e., creative digital designers).

This study develops a scale to measure perception of niche. The scale has been inspired by the conceptual work of Mason [30] which proposed a framework of status-seeking behavior in relation to niche brands and also employs the findings of Vigneron et al.'s [47] recent study on niche product seeking behaviors of users. We used the definition that Schaefers [40] has suggested for niche product: Niche products are products that are possessing a higher degree of specificity and uniqueness than corresponding massmarket products. In doing so, we attempted to establish a balance between personal and interpersonal motives for consumption of niche products. This model is also consistent with previous research on similar concepts (e.g., luxury) that demonstrated that behavior varies between different people depending on their 
susceptibility to interpersonal influence [47]. The conceptual framework used (Figure 1), which was derived from the literature, demonstrates the existence of three latent niche dimensions reflecting on nonpersonal oriented perceptions, i.e., Conspicuousness and Uniqueness, and also on personal oriented perception, i.e., Digital Extended Self.

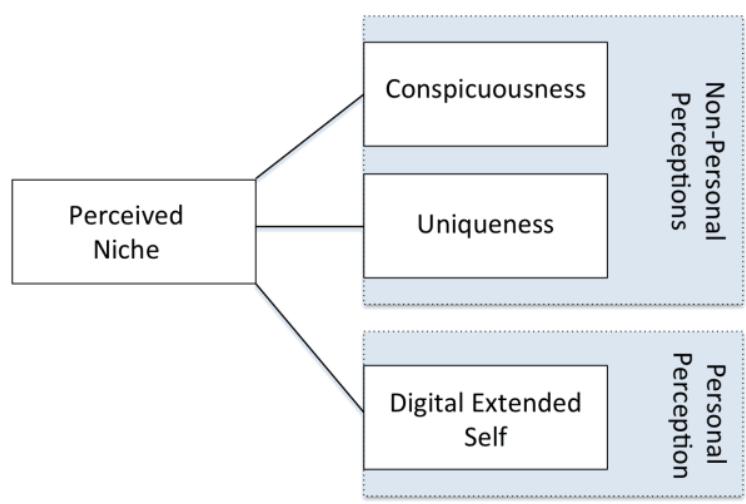

Figure 1. Framework of perceived niche index

\subsection{Conspicuousness}

Researchers [e.g., 31, 5, 37, 40] argued that people may have desires for conspicuous consumptions in order to influence other's perceptions about themselves, acquiring and using niche products can serve such a desire. SNS users would thus decide to use niche SNSs to achieve their intended level of differentiation from others. As niche SNSs might be seen as a unique and differentiated product than similar mainstream SNSs (e.g., Facebook), their use may seem as a mechanism for satisfying one's yearning for distinctiveness [40]. This would imply that niche products are not only used because they address the users' functional needs better than corresponding mainstream alternatives but also because of their symbolic meaning [18]. Additionally, using niche products can provide consumers with the feeling that they are pioneers (since few other people have used such products), and could signal their possession of inside information [38]. Thus, the need to differentiate oneself and better express one's identity may be more prominent for niche SNSs.

\subsection{Uniqueness}

A great deal of literature, including work on uniqueness [e.g., 43], optimal distinctiveness [e.g., 6], and intergroup differentiation (see Jetten and et al. [24], for a meta-analytic review) would predict that people diverge from others who are similar. The literature on individuals, drives for differentiation suggests people diverge as a result of too much similarity. The uniqueness literature [e.g., 43, 28] argues that people have the drive to be unique and that too much similarity leads to a negative emotional reaction. When people feel overly similar, they strive to differentiate themselves. Hence, people have a tendency to drop mainstream products in favor of more niche ones to positively differentiated themselves [44].

As Schaefers [40] has pointed out the acquisition and use of niche products might be seen as a strategy to improve person's self and social images and differentiate her from other mainstream product users. Prior research found that scarcity and limited availability of a product enhance user's preferences for it [34]. In the context of SNSs, uniqueness dimension of niche refers to the concept of exclusivity of the information system, which enhances the desire for it [47]. Hence, the niche SNSs has not been designed to be used by the general population. For instance, Facebook and Ello both are SNSs. However, the former system is designed for (almost) everyone, while Ello is for individuals who have interests in digital arts and it requires potential members receive an invitation from a current member of Ello to be able to sign up in it.

\subsection{Digital extended self}

As discussed above, SNS adopters may use niche systems because of its symbolic meaning [18]. This way, the user tries to integrate the symbolic meaning into his/her own identity. Social referencing and building one's own self-appear to be an important factor in defining a person's niche product consumption [47]. The concept of extended self (in the context of SNS we call it 'digital extended self') indicates that individuals view their group membership (i.e., being part of a users' cluster of specific SNS) as part of their identity $[3,35]$.

Belk [3] updated the concept of extended self to the digital realm by introducing digital extended self. He noted that an association with certain virtual communities might be seen as an extension of the user's real self. Therefore, it is important for such a person to sense that being part of such a network helps him/her to achieve and communicate the desired extended self. In pre-digital times, we could try out new identities by possessing specific cars or clothes, while in the present digital age, our online virtual appearance provides an easier and less risky environment for such self-experimentation. 


\section{Scale development}

The study developed and validated the scale following the procedure set forth by Moore and Benbasat [32]. To develop measures for perceived niches, we began with a review of the relevant literature followed by a qualitative data collection (focus groups). Then, we examined the generated items and created an initial set of items in the item generation step. Later, we conducted Q-sort analysis, and two validation studies (Table 1). The following sections provide details on the entire process.

Table 1. Summary of the scale development process

\begin{tabular}{|c|c|c|c|}
\hline $\begin{array}{l}\text { Stage of scale } \\
\text { development }\end{array}$ & Sample & Activities & Results \\
\hline $\begin{array}{l}\text { Preliminary } \\
\text { quantitative } \\
\text { data collection }\end{array}$ & $\begin{array}{l}\text { Business } \\
\text { students }(n \\
=11)\end{array}$ & $\begin{array}{c}\text { Literature } \\
\text { review \& } \\
\text { Focus group } \\
\text { sessions }\end{array}$ & $\begin{array}{l}\text { List of } 21 \\
\text { candidate } \\
\text { items }\end{array}$ \\
\hline $\begin{array}{l}\text { Item } \\
\text { generation }\end{array}$ & $\begin{array}{l}\text { Expert } \\
\text { judges } \\
(n=2)\end{array}$ & Face validity & $\begin{array}{l}21 \text { items } \\
\text { reduced } \\
\text { to } 11 \\
\text { items }\end{array}$ \\
\hline Q- sort & $\begin{array}{l}\text { Expert } \\
\text { judges ( } n \\
\quad=8)\end{array}$ & $\begin{array}{c}\text { Item } \\
\text { replacement } \\
\text { ratios and } \\
\text { Kappa } \\
\text { (Construct } \\
\text { validity) }\end{array}$ & $\begin{array}{l}11 \text { items } \\
\text { reduced } \\
\text { to } 7 \text { items }\end{array}$ \\
\hline $\begin{array}{c}\text { Stage of } \\
\text { scale } \\
\text { assessment }\end{array}$ & Sample & Activities & Results \\
\hline $\begin{array}{l}\text { Longitudinal } \\
\text { Pilot test }\end{array}$ & $\begin{array}{l}\text { Amazon's } \\
\text { MT }(n= \\
\text { 29) }\end{array}$ & $\begin{array}{c}\text { EFA, } \\
\text { Cronbach's } \\
\text { Alpha, } \\
\text { Discriminant } \\
\text { validity }\end{array}$ & $\begin{array}{c}7 \text { items } \\
\text { reduced } \\
\text { to } 4 \text { items }\end{array}$ \\
\hline $\begin{array}{l}\text { Longitudinal } \\
\text { Validation test }\end{array}$ & $\begin{array}{c}\text { Amazon's } \\
\text { MT }(n= \\
\text { 259) }\end{array}$ & $\begin{array}{c}\text { Composite } \\
\text { reliability, } \\
\text { Convergent } \\
\text { validity, CFA }\end{array}$ & $\begin{array}{l}\text { Final list } \\
\text { of } 4 \text { items }\end{array}$ \\
\hline
\end{tabular}

\subsection{Study 1 - Preliminary qualitative data collection: focus groups}

Since there has been limited research on niche technology, we conducted a series of interviews to explore the domain of individuals' niche perceptions. We recruited participants from a large Midwestern university's undergraduate information systems courses. We identified 11 students (6 females and 5 males, median age 22 years old) as active users of niche technologies (e.g., Augmented reality apps, ResearchGate, Ello, etc.). The verbal questions used in the focus group sessions at the first phase which, consisted of open-ended questions designed to capture the personal description of niche-ness from their perspective. During the focus group sessions, we used questions such as: "What does compel you to use more niche IS?", "Why do you feel some SNSs are more niche than others?", and "How does a niche app satisfy your needs differently from a less niche one?", etc.

Following the focus group sessions, the researcher and assistant moderators (two research assistants not aware of the theoretical background) met to discuss the transcripts to detect preliminary themes and aspects related to niche technology perceptions. The focus groups resulted in a total of 25 statements (8 reflecting conspicuousness, 10 reflecting uniqueness, and 7 reflecting Digital extended self) representing the three aspects of the perceived niche construct (Figure 1).

The researcher and assistant moderators further reviewed the transcripts and identified redundant statements (e.g., "This app has distinct features compared to other apps" and "This app has different functions than others") and reduced the list to 21 items. Then, we started generating the initial list of items.

\subsection{Item generation and selection}

The goal of this research is to produce a short, easy-to-administer instrument. Because we were interested in a predictive and simple measure of the construct and not in the unique properties of its different manifestations, we sought to conceptualize perceived niche as a reflective construct and developed a scale in which items reflecting various aspects of the construct were summed into a single score. This conceptualization of the perceived niche construct was in accordance with prior research on similar constructs, such as uniqueness, perceived luxury and attractiveness [e.g., 13, 25]. In addition, this approach corresponds to what Bagozzi and Heatherton [1] call the total aggregation model of perceptual construct measurements. Formative, rather than reflective, conceptualization may make overall scores on the scale psychologically ambiguous and the relationships between perceived niche scores and other variables difficult to interpret (see Bagozzi \& Heatherton [1] and Lynn et al. [28]). Besides, reviewing the relevant research reveals that there could be high levels of covariation among the identified aspects of perceived niche [e.g., 17], which is a required criterion to consider a construct as reflective [23]. By proposing a reflective scale, the items were developed to be reflective (effect) indicators of the functions of the 
latent variable. Therefore, changes in the latent variable were reflected in changes of the observable indicators.

First, a pool of potential items (21 items) for measuring perceived niche was created based on our qualitative focus group interviews, the definition of the construct, and extant literature. Building on Porter's [39] generic strategic approach and other relevant studies [e.g., 9, 14, 36, 47] on niche marketing strategies, we can determine that niche technologies represent consciousness, uniqueness, and digital extended self. These three aspects refer to the main defining criterion for a niche technology, that is, specificity. Hence, the perceived niche is defined as a user's belief about the degree of specificity of the attributes of a technology.

Then, after creating a pool of potential items, we eliminated redundant items and selected items that had good face validity for expert review. We validated the items' face validity by asking two management information systems faculty to review them. In total 11 items were selected.

\subsection{Q-sort analysis}

A two-step Q-sort [33] was conducted, with four judges (Ph.D. students of IS) in each round. The Q-sort was designed on Qualtrics and asked the four judges in the first round to sort items into groups. They could create as many groups as they want but were required to name the resulting groups. In the second round, four different judges were given the name and description of the focal category (Perceived Niche) and a second "too ambiguous/does not fit" category. Then, they assigned the cards to those two categories.

To assess construct validity, we examined the item placement ratios, as described by Moore and Benbasat [33]. The item placement ratio is an assessment of the overall frequency with which judges place items within their intended theoretical constructs (or in other words, place them in the intended groups). The method required analysis of how many items were placed by the panel of judges for each round within the "target" construct. If an item is consistently placed into its intended construct, the researcher may reasonably be confident that the item has high construct validity. Scales based on categories, which have a high degree of "correct" placement of items within them, can be considered to have a high degree of construct validity, with a high potential for good reliability scores. It must be emphasized that this procedure is more of a qualitative analysis than a rigorous quantitative procedure. There are no established guidelines for determining "good" levels of placement, but the matrix can be used to highlight any potential problem areas
[34]. To further assess the reliability of the sorting by the judges for each pair of judges in each sorting step, their level of agreement in categorizing items was measured using Cohen's Kappa [9]. Kappa scores greater than .65 are considered acceptable.

3.3.1. Q-sort results. Four judges were involved in each of the first two sorting rounds, which included items developed for the perceived niche construct. In the first round, two judges created one category, while the other two had two. In this study, the first round yielded an overall item placement ratio of $64 \%(=18$ (total hits) / 28 (total item placement)). An average Kappa score of 0.62 was also obtained. In this round, two items were dropped from the item pool because items were found to ambiguous (fitting in an unintended category) by two (out of four) judges [34].

The four new judges in the second round were asked to sort the remaining five items based on construct definition, which was provided. The overall item placement ratio within target construct for the second round was $75 \%$ (= 15 (total hits) / 20 (total item placement)) and Kappa averaged 0.87. Four items were identified as being too ambiguous by two judges; hence, they were dropped. The improved values of the item placement rate and also the value of Kappa (which is well above the threshold of 0.65) indicated that items were generally being placed as they were intended. Thus, it was concluded that the development process had resulted in a measurement, which demonstrated construct validity, with a high potential for very good reliability coefficients.

\section{Assessment of the scale}

\subsection{Research technology}

The study conducts two longitudinal online testes (i.e. pretest and main surveys) to evaluate the developed scale. Ello, a social networking website, was the research technology. We chose Ello, as it is a relatively new social networking tool (launched in 2014) that successfully attracted specific clusters of individuals in the early days of its launch. Ello also qualifies as a niche SNS. Based on Ello's published manifesto, it is ads-free, it does not perform any data mining, and it does not use any algorithms designed to make decisions about what its users should see. Put differently, in sharp contrast to other mainstream SNSs (e.g., Facebook), Ello does not turn its users into products [15]. Additionally, Ello aims to attract a very specific segment of SNS users that are people who are interested in digital art. As the creator of Ello, Paul 
Budnitz, expresses: "We don't want everyone on Ello. That's not what we're building" [41].

Ello is the only online community designed and built for art creators and enthusiasts, by creators. It consists of a robust and growing community of artists, designers, writers, musicians, GIF makers, architects, photographers, and illustrators without the commercialized features that discourage its users from the mainstream social networks. Ello has found its niche, thanks to a very exclusive community. Ello also offers some additional features for purchase, such as the ability to have multiple profiles. The posted artworks and ideas are mostly original. As one of the posts on Ello reads: "There is very little re-posting and there is little on Ello that is trivial or superficial." Similarly, another Ello user mentions: "Ello is remarkably different what one is likely to find elsewhere" [20]. For all of these reasons, we argue that Ello meets all of the criteria for our study, as a niche technology with potential for observing acceptable levels of variance in its users' niche perceptions.

\subsection{Study 2: pilot test}

We recruited 40 participants from Amazon's Mechanical Turk (MT), resulting in a usable sample of 29 after screening their responses $(59 \%$ of respondents were female, median age 34 years old and median education 2-year college degree). MT is an online crowd-sourcing platform, to conduct a pilot test of the instrument. The use of MT has several benefits over using student subjects in research. Its population is more diverse and reliable, thus increasing the external validity of the behavioral research study [32].

The participants were provided with the URL of the first survey questionnaire (i.e., demographic questions). Then, the participants were encouraged to create an account on Ello in order to be qualified to participate in the second phase of data collection. Eight weeks later, the respondents to the first survey were invited to participate in the second survey. Three items were first used to make sure that the participant was actually using Ello. Those who did not use Ello during the previous eight weeks were excluded from further participation. The respondents who passed this initial screening process were then provided with a URL to complete the second survey, which included the developed scale of perceived niche. We used sevenpoint Likert scales, with 1 representing "strongly disagree," 4 "neutral," and 7 "strongly agree."

4.2.1. EFA results. An exploratory (principle components) factor analysis (EFA) using Varimax rotation in SPSS was conducted on the collected data to assess the reliability of the scale [33]. Varimax is the most popular factor rotation methods focusing on simplifying the columns in a factor matrix. This method is generally considered superior to other factor rotation methods in achieving a simplified factor structure and gives a clearer separation of the factors compared to other rotation methods such as QUARTIMAX [19]. Loadings greater than 0.707 are considered adequate [8]. For item purification, we used Cronbach's Alpha to assess the reliability of the items. A Cronbach's Alpha higher than .70 indicates that an item has good reliability [10]. Items with low interitem and item-total correlations, high "Cronbach's Alpha if item deleted" statistics, or small standard deviation scores (and thus low explanatory power) were candidates for deletion [33].

In order to enhance the rigor of this initial investigation, we include measures for several related variables such as task-technology fit (e.g., Ello's functions are very sufficient), confirmation (e.g., Compared to my initial expectations, the ability of Ello to improve my performance was much better than expected), Network effect (e.g., The more people use Ello, the more valuable it is to users). These variables were included to provide a more rigorous assessment of discriminant validity and ensure that items for the engagement dimensions were strictly measuring niche perceptions.

Three items with low loadings and high "Cronbach's Alpha if item deleted" statistics were deleted with the content validity in mind. We used the final version of the niche perception scale, consists of four validated items, to further assess in a large-scale final validation study.

\subsection{Study 3: validation test}

A validation dataset was collected to confirm the measurement model. Similar to the pilot test, we conducted a longitudinal (i.e., two surveys) data collection through MT. Adopting the same procedure we used in the pilot study, respondents to the first survey were invited to participate in the second survey. Out of initial 350 participants, 38 declined to participate in the second survey and were thus eliminated from further statistical analysis. Out of the individuals who answered both surveys, thirteen failed to answer the bogus questions (i.e., items used to identify inattentive respondents) correctly, seven marked almost the same answers throughout the entire survey, five did not finish the survey, and twenty-eight did not use Ello since taking the first survey. In total, 259 surveys were judged usable. Participant characteristics are presented in Table 2. 
Table 2. Demographic profile of the respondents

\begin{tabular}{lr}
\hline & \multicolumn{1}{c}{$\mathbf{N}(\mathbf{\%})$} \\
\hline Gender & $120(46.3 \%)$ \\
Female & $139(53.7 \%)$ \\
Male & \\
Age & $43(16.6 \%)$ \\
$18-24$ & $106(40.9 \%)$ \\
$25-34$ & $61(23.6 \%)$ \\
$35-44$ & $34(13.1 \%)$ \\
$45-54$ & $12(4.6 \%)$ \\
$55-64$ & $3(1.2 \%)$ \\
$65+$ & \\
Education & $1(.4 \%)$ \\
$<$ High school & $25(9.7 \%)$ \\
High School & $100(38.6 \%)$ \\
College & $88(34.0 \%)$ \\
Bachelor's & $44(17.0 \%)$ \\
Master's & $1(.4 \%)$ \\
Ph.D. & \\
\hline
\end{tabular}

4.3.1. Analysis and Results. The reliability and validity of the scale were examined via confirmatory factor analysis (CFA) using AMOS 24 statistical software. The result shows that all items' loadings on their respective constructs were greater than the suggested threshold of 0.707 (See Table A1 in Appendix). The composite reliability (CR) estimates ranged from .79 to .93 , while the AVEs range from .61 to .86, indicating acceptable convergent validity [2]. Also, discriminant validity was established based on the values for the square root of AVE for each construct exceeding its correlations with other constructs in the model [8]. To assess the overall fit of the CFA model, we examined several commonly used fit indexes [22]. All model fit indexes were within accepted thresholds (Table 3 ).

Table 3. Goodness-of-Fit indicators for the CFA

\begin{tabular}{lcc}
\hline \multicolumn{1}{c}{ Measure } & Threshold & Estimate \\
\hline MIN/DF & Between 1 and 3 & 1.47 \\
CFI & $>0.95$ & 0.96 \\
SRMR & $<0.08$ & 0.06 \\
RMSEA & $<0.06$ & 0.04 \\
PClose & $>0.05$ & 0.37 \\
TLI & $>0.95$ & 0.97 \\
\hline
\end{tabular}

Table 4. Scale items, descriptive statistics, and factor loadings

\begin{tabular}{|c|c|c|c|c|c|c|c|c|}
\hline \multirow{2}{*}{ Item Wording } & \multicolumn{4}{|c|}{ Study 2: Pilot Test } & \multicolumn{4}{|c|}{ Study 3: Validation Test } \\
\hline & Range & Mean & $\mathrm{SD}$ & $\lambda$ & Range & Mean & $\mathrm{SD}$ & $\lambda$ \\
\hline $\begin{array}{l}\text { Ello is designed for a specific cluster of SNS } \\
\text { users. }\end{array}$ & $1-6$ & 3.24 & 1.17 & .83 & $1-7$ & 3.83 & 1.88 & .79 \\
\hline Ello is distinct from other SNSs. & $1-7$ & 3.4 & 1.32 & .87 & $1-7$ & 4.01 & 1.75 & .81 \\
\hline $\begin{array}{l}\text { Ello's posts are different from posts of other } \\
\text { SNSs. }\end{array}$ & $1-7$ & 3.6 & 1.29 & .88 & $1-7$ & 3.88 & 1.92 & .91 \\
\hline Using Ello makes me feel different. & $2-7$ & 3.36 & 1.22 & .75 & $1-7$ & 4.51 & 2.12 & .80 \\
\hline
\end{tabular}

In Table 4 we provide a complete listing of all items retained for the final version of the scale as well as their respective ranges, means, standard deviations, and lambda loadings to assist in the establishment of scale norms.

\section{Discussion}

This paper is a conceptual and empirical attempt to understand users' perceptions of niche in the IS context. The current study has developed and validated a scale to measure the perceived niche construct. Hence, our study extends current research on conspicuous consumption [46] and introduces the concept of niche to IS research [7, 18, 40]. The current paper contributes to the growing literature on the role of niche IS consumption that helps users of specific technologies to achieve the intended levels of differentiation from other. Prior research exploring IS consumption has failed to recognize the conspicuous form of technology use.

Another important contribution of this study is to delineate the domain of niche technology. We conceptualized the perceived niche as a phenomenon with three dimensions. Basing on the extant research the study develops a conceptual framework (Figure 1), which demonstrates the existence of three latent niche dimensions reflecting on non-personal oriented perceptions, i.e., Conspicuousness and Uniqueness, and also on personal oriented perception, i.e., Digital

Extended Self. We argued that perceived niche should be conceptualized as a reflective construct, which is composed of above-mentioned dimensions.

After extensive reviews of past research on relevant literature and conducting a qualitative and two quantitative longitudinal studies we generated a fouritem model of the perceived niche construct. It is 
important to note that the perception of niche dimensions discussed and identified here represent a comprehensive set of factors that may influence individuals IS behaviors (e.g., adoption and usage).

More specifically, we contribute to theory by developing a survey scale that potentially will assist researchers to investigate the role of niche perceptions in the SNS adoption setting. The forthcoming demise of some mainstream SNSs and recognition of more niche systems is the phenomenon, which is worthy of further examinations via measuring the effect of relevant variables, such as 'perceived niche'. Due to the advent and popularity of recent niche SNSs (e.g., Ello, Flixster, imeem), it would be interesting to examine the dynamics of individuals' adoption of those technologies. To the best of our knowledge, niche technology behaviors of individuals (e.g., adoption and usage) have not been studied in prior IS research. By developing and validating a short, but accurate measurement, this study provides the IS researchers with a suitable tool for future investigation in the niche technology domain. Hence, the study can be considered as one of the first to look at niche technology adoption behavior.

Last and most importantly, the developed scale has the potential to further increase the theoretical understanding of the influence of technological characteristics, i.e. the degree of niche-ness of a technology, on adopters' behavior by facilitating the operationalization of the relevant concepts. In other words, theoretical models aimed at understanding why people prefer niche systems rather than mainstream alternatives can be empirically analyzed through the developed scale. In addition, future research by incorporating the role of perceived niche in their models may help system designers to understand what characteristics of the system lead to higher levels of perceived niche, and also what initiatives can lead to higher perceived niche levels during the implementation of the new information systems.

\section{References}

[1] R. P. Bagozzi, and T. F. Heatherton, "A general approach to representing multifaceted personality constructs: Application to state self-esteem." Structural Equation Modeling: A Multidisciplinary Journal,1(1), 1994, pp. 35-67.

[2] R. P. Bagozzi, and Y. Yi, "On the evaluation of structural equation models", Journal of the academy of marketing science, 16(1), 1988, pp. 74-94.

[3] R. Belk, "Ownership: The Extended Self and the Extended Object." In Psychological ownership and consumer behavior, pp. 53-67. Springer, Cham, 2018.
[4] J. Berger, and C. Heath, "Who drives divergence? Identity signaling, outgroup dissimilarity, and the abandonment of cultural tastes." Journal of personality and social psychology, 95(3), 2008, pp. 593-614.

[5] M.B. Brewer, "Optimal distinctiveness, social identity, and the self", in Leary, M.R. and Tangney, J.P. (Eds), Handbook of Self and Identity, Guilford Press, New York, NY, 2003, pp. 480-491.

[6] M.B. Brewer, "The social self: On being the same and different at the same time", Personality and social psychology bulletin, 17(5), 1991, pp. 475-482.

[7] H.R. Chaudhuri, and S. Majumdar, "Of diamonds and desires: understanding conspicuous consumption from a contemporary marketing perspective", Academy of Marketing Science, 1(11), 2006, pp. 1-18.

[8] W. W. Chin, The partial least squares approach to structural equation modeling. In: Marcoulides, G.A. (Ed.), Modern Methods for Business Research. Lawrence Erlbaum Associates, Mahwah, NJ, 1998.

[9] J. Cohen, "Weighted kappa: Nominal scale agreement provision for scaled disagreement or partial credit”, Psychological bulletin, 70(4), 1968 pp. 213-220.

[10] L. J. Cronbach, and L. Furby, "How we should measure" change": Or should we?", Psychological Bulletin, 74(1), 1970, pp. 68-80.

[11] T. Dalgic, and M. Leeuw, "Niche marketing revisited: concept, applications and some European cases", European Journal of Marketing, 28 (4), 1994, pp. 39-55.

[12] M. Debruyne, and D.J., Reibstein, "Competitor see, competitor do: Incumbent entry in new market niches", Marketing Science, 24(1), 2005, pp. 55-66.

[13] V. Dogan, B. Y. Ozkara, and M. Dogan, "Luxury consumption tendency: conceptualization, scale development and validation." Current Psychology, 2018, pp. 1-19.

[14] A. Echols, and W. Tsai, "Niche and performance: The moderating role of network embeddedness", Strategic Management Journal, 26(3), 2005, pp. 219-238.

[15] Ello Manifesto, 2014, Retrieved from https://ello.co/wtf/about/ello-manifesto/

[16] F. Flavio, G. J. Da Silveira, and D. Borenstein, "The mass customization decade: An updated review of the literature", International Journal of Production Economics 138, 12(1), 2012, pp. 14-25.

[17] N. Franke, and M. Schreier, "Product uniqueness as a driver of customer utility in mass customization", Marketing Letters, 19(2), 2008, pp. 93-107.

[18] H. Gierl, and V. Huettl, "Are scarce products always more attractive? The interaction of different types of scarcity 
signals with products' suitability for conspicuous consumption", International Journal of Research in Marketing, 27 (3), 2010, pp. 225-235.

[19] J. F. Hair, W. C. Black, B.J. Babin, , R.E. Anderson, and R. L. Tatham, "Multivariate data analysis" (Vol. 5, No. 3, pp. 207-219). Upper Saddle River, NJ: Prentice hall, 2009.

[20] D. Hopkinson, 2016, Retrieved from https://ello.co/dave63/post/lly4g-lnkyjwojf2bk4w5q.

[21] T. Hsu, 'For Many Facebook Users, a 'Last Straw' That Led Them to Quit', 2018, Retrieved from https://www.nytimes.com/2018/03/21/technology/usersabandon-facebook.html

[22] L.T. Hu, and P. M. Bentler, "Cutoff criteria for fit indexes in covariance structure analysis: Conventional criteria versus new alternatives", Structural equation modeling: a multidisciplinary journal, 6(1), 1999, pp. 1-55.

[23] C. B. Jarvis, S. B. MacKenzie, and P. M. Podsakoff, "A critical review of construct indicators and measurement model misspecification in marketing and consumer research", Journal of consumer research, 30(2), 2003, pp. 199-218.

[24] J. Jetten, R. Spears, and T. Postmes,'Intergroup distinctiveness and differentiation: a meta-analytic integration', Journal of personality and social psychology, 86(6), 2004, pp.862-889.

[25] J.N. Kapferer, "Abundant rarity: the key to luxury growth”, Business Horizons, 55 (5), 2012, pp. 453-462.

[26] S. Kemp, "Perceiving luxury and necessity", Journal of Economic Psychology, 19(10), 1998, pp. 591-606.

[26] P. Kotler, and K.L. Keller, Marketing Management, 12th ed., Pearson Prentice Hall, Upper Saddle River, NJ, 2006.

[28] M. Lynn, and C. R. Snyder, "Uniqueness seeking”, In C. R. Snyder and J. Lopez, S (Eds.), Handbook of positive psychology, pp. 395-410. New York, NY: Oxford University Press, 2002.

[29] D. MacMillan, "Lenovo CEO says tablets make up niche market dominated by Apple", Retrieved from www.businessweek.com/news/2012-01-13/

lenovo-ceo-says-tablets-make-up-niche-market-dominatedby-apple.html.

[30] R.S. Mason, "Modelling the demand for status goods" Working paper, Department of Business and Management Studies, University of Salford, UK, 1992.

[31] R. S. Mason, "Conspicuous Consumption: A Study of Exceptional Consumer Behaviour", Gower, Farnborough, 1981.
[32] W. Mason, and S. Suri, "Conducting behavioral research on Amazon's Mechanical Turk", Behavior research methods, 44(1), 2012, pp. 1-23.

[33] G. C. Moore, and I. Benbasat, "Development of an instrument to measure the perceptions of adopting an information technology innovation", Information systems research, 2 (3), 1991, pp. 192-222.

[34] I. Pantzalis, "Exclusivity Strategies in Pricing and Brand Extension", unpublished doctoral dissertation. University of Arizona, Tucson, AZ, 1995.

[35] B. Parkinson, D. E. Millard, K. O'Hara, and R. Giordano, "The Digitally Extended Self: A Lexicological Analysis of Personal Data," Journal of Information Science 1(9), 2017, pp. 1-18.

[36] E. Parrish, "Retailers' use of niche marketing in product development", Journal of Fashion Marketing and Management: An International Journal, 14(4), 2010, pp. 546561.

[37] G. Patsiaouras, and J.A. Fitchett, "The evolution of conspicuous consumption", Journal of Historical Research in Marketing, 4 (1), 2012, pp. 154-176.

[38] C. W. Phang, C. Zhang, and J. Sutanto. "The influence of user interaction and participation in social media on the consumption intention of niche products." Information \& Management, 50 (8) , 2013, pp. 661-672.

[39] M.E. Porter, Competitive Strategy: Techniques for Analyzing Industries and Competitors, Free Press, 1980.

[40] T. Schaefers, "Standing out from the crowd: niche product choice as a form of conspicuous consumption", European Journal of Marketing, 48(9), 2014, pp. 1805-1827.

[41] C. Shea, "Is a social network that doesn't share user data possible? We asked someone who's trying”, 2018, Retrieved from

https://www.vox.com/conversations/2018/3/27/17168790/ell o-facebook-alternative-data-privacy-cambridge-analyticadeletefacebook.

[42] I. Simonson, "Determinants of customers' responses to customized offers: conceptual framework and research propositions", Journal of Marketing, 69(1), 2005, pp. 32-45.

[43] C. R. Snyder, and H. Fromkin, Uniqueness: The pursuit of difference, New York, NY: Plenum, 2012.

[44] K.T. Tian, W.O. Bearden, and G.L. Hunter, "Consumers' need for uniqueness: Scale development and validation", Journal of Consumer Research, 28(6), 2001, pp. $50-66$. 
[45] K. Toften, and T. Hammervoll, "Niche marketing research: status and challenges", Marketing Intelligence \& Planning, 31(3), 2013, pp. 272-285.

[46] T.B., Veblen, The Theory of the Leisure Class, Houghton Mifflin, Boston, MA, 1899.

[47] F. Vigneron, and L.W. Johnson, Measuring perceptions of brand luxury, In Advances in Luxury Brand Management, Palgrave Macmillan, Cham, 2017.

\section{Appendix}

Table A1 Items and Factor Loadings

\begin{tabular}{|l|c|c|c|c|}
\hline & CNF & NCH & TTF & NE \\
\hline CNF1 & .785 & .051 & .082 & .011 \\
\hline CNF2 & .884 & .018 & .173 & .030 \\
\hline CNF3 & .870 & .108 & .103 & .085 \\
\hline CNF4 & .709 & .185 & .215 & .151 \\
\hline NCH1 & -.026 & .791 & -.053 & .011 \\
\hline NCH2 & .060 & .813 & -.087 & -.041 \\
\hline NCH3 & .009 & .912 & -.121 & -.012 \\
\hline NCH4 & .070 & .801 & -.107 & -.116 \\
\hline TTF1 & .085 & -.025 & .719 & .045 \\
\hline TTF2 & .051 & -.076 & .803 & .027 \\
\hline TTF3 & .114 & -.130 & .839 & .048 \\
\hline TTF4 & .077 & -.107 & .824 & .106 \\
\hline TTF5 & .102 & -.067 & .808 & .045 \\
\hline TTF6 & .037 & -.026 & .785 & .080 \\
\hline TTF7 & .066 & -.043 & .739 & .121 \\
\hline TTF8 & .177 & -.125 & .723 & .091 \\
\hline NE1 & .105 & -.010 & .099 & .779 \\
\hline NE2 & .175 & .051 & .017 & .711 \\
\hline NE3 & .046 & -.103 & .031 & .841 \\
\hline NE4 & .058 & -.067 & .038 & .805 \\
\hline NE5 & .191 & -.250 & .090 & .735 \\
\hline Note: CNF & Confirmation & NCH: Perceived \\
\hline
\end{tabular}

Note: CNF: Confirmation; NCH: Perceived Niche; TTF: Task-Technology Fit; NE: Network effect. 